\title{
Physicochemical parameters and microbial loads of marine cage farm environment at Polem, Goa
}

\author{
MAMATHA H. HAZARI AND J. L. RATHOD \\ Department of Post Graduate Studies and Research in Marine Biology, P. G. Centre of Karnatak University \\ Kodibag, Karwar - 581 303, Karnataka, India \\ e-mail: jagannathrathod9@gmail.com
}

\begin{abstract}
Present study was undertaken at the marine cage farm of Polem Village, Goa. Water and sediment samples were analysed for evaluation of the physicochemical characteristics and total cultivable heterotrophic bacteria. No significant variation was observed in the physicochemical parameters of water except for inorganic phosphate $(\mathrm{p}<0.05)$. Total cultivable bacterial count ranged from 2.06 to $19.27 \times 10^{4} \mathrm{cfu} \mathrm{g}^{-1}$ and from 1.14 to $8.41 \times 10^{4} \mathrm{cfu} \mathrm{g}^{-1}$, while total presumptive vibrio count ranged from 0.15 to $1.57 \times 10^{4} \mathrm{~g}^{-1}$ and 0.09 to $0.78 \times 10^{-4} \mathrm{~g}^{-1}$. Results of the present investigation revealed that all the parameters studied were within the optimum range and cage farming with limited number of cages does not have major impacts on the water and sediment quality.
\end{abstract}

Keywords: Bacteria, Cage culture, Polem, Sediment, Vibrio

Aquaculture is one of the fastest growing food production sector in the world, contributing $30 \%$ of the total fish production. Cage aquaculture is a method of intensive farming (Liao et al., 2004) expanded in India in an expressive way during the last decade (Philipose et al., 2013). Intensive fish culture in cages can lead to the eutrophication of water bodies, increased primary production and harmful algal blooms. Fish metabolites, like ammoniacal nitrogen and urea along with the uneaten food from the culture systems are issues of concern around the world, in addition to destruction of natural habitats and alterations in the structure and dynamics of local organisms (Gorlach-Lira et al., 2013).

Water quality being an important criterion in aquaculture system, its deterioration in culture system leads to stress, resulting in invasion by opportunistic pathogens (Arulampalam et al., 1998). It has been reported that nitrogen and phosphorous released from fish cage can affect the chemical parameters of sediment (Porrello et al., 2005; Anusuya Devi et al., 2015). Further, composition and amount of nutrients discharged into waters from the culture systems vary depending on the production outputs, feed conversion ratio and the phosphorus and nitrogen content of feed (Teodorowicz, 2013).

Microorganisms play a very important role in water bodies by influencing the transformation of nutrients, disease occurrence and waters quablity parameters (Moriarty, 1997; Gorlach-Lira, 2013). The wastes from floating cages often promotes growth of microbial organisms (Arulampalam et al., 1998). Composition of the microbes in the sediment may serve as an indicator of health of the ecosystem (Zeng et al., 2010). Apart from a few studies conducted by Prema et al. (2010) and Philipose et al. $(2012 ; 2013)$ there are no information on the impact of fish cage aquaculture on water quality and nutrient recycling, from the Indian subcontinent. Hence, the present study was envisaged to analyse the effect of cage culture on the water quality parameters and the microbial load in the sediment.

Present study was carried out in Polem Village, Goa, India (Fig. 1) from September 2014 to May 2016. Twenty five circular GI cages of $6 \mathrm{~m}$ dia were in operation during the study period. Asian seabass Lates calcarifer, snubnose pompano Trachinotus blochii and cobia Rachycentron canadum were cultured in these cages at a stocking density of 14,17 and 7 nos. $\mathrm{m}^{-3}$, respectively. Two stations were selected for the present investigation viz., station 1 at the cage culture site (14 $54^{\prime} 21.12^{\prime \prime} \mathrm{N}$; $74^{\circ} 04^{\prime} 32.20^{\prime \prime} \mathrm{E}$ ) and station 2 , a reference site without farming activities (14 54'06.30”N; 740 04'02.22’'E).

Water and sediment samples were collected at monthly intervals from both the stations during September 2014 to May 2016, except during the monsoon season (June to August). Surface and bottom water samples were collected from both stations using water sampler. Sediment samples were collected using Peterson grab $\left(0.1 \mathrm{~m}^{2}\right)$. Samples were collected in sterile polythene containers and bags, labeled and stored in chilled condition till analysis. 


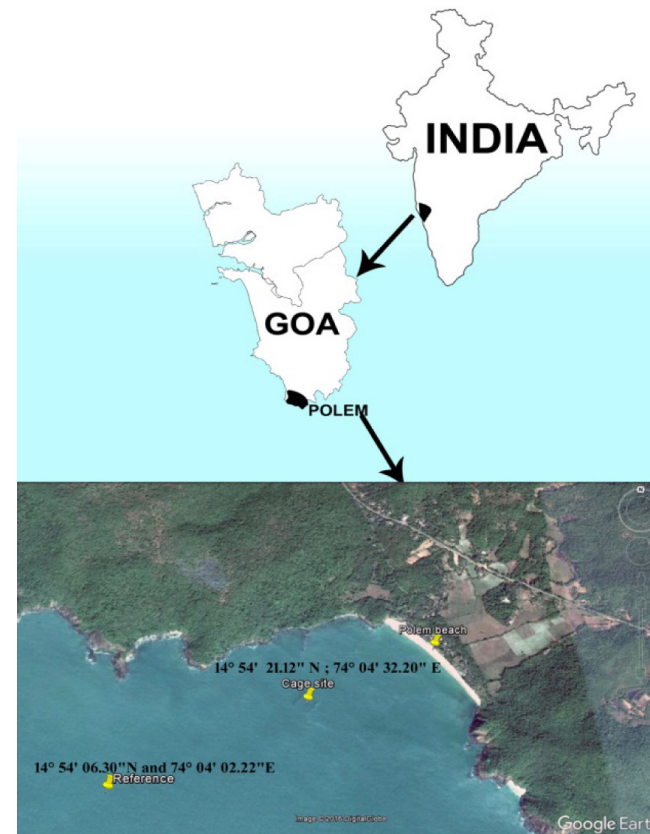

Fig. 1. Map showing the study area

Water temperature, $\mathrm{pH}$, salinity and dissolved oxygen (DO) were measured using potable instruments. Nutrients such as ammonia-nitrogen, nitrite-nitrogen and dissolved inorganic phosphate $\left(\mathrm{PO}^{-4}\right)$ were analysed in the laboratory, as per standard methods (APHA, 1984). For enumeration of total cultivable bacteria and presumptive vibrio count, $1 \mathrm{~g}$ of sediment sample was suspended in $10 \mathrm{ml}$ phosphate buffered saline $(\mathrm{pH} 7.5)$, sonicated and serial two-fold dilutions were made in sterile normal saline. The serially diluted samples $(0.1 \mathrm{ml})$ were inoculated on to Zobell marine agar (ZMA, Himedia, India) and thiosulfate citrate bile salts sucrose agar (TCBS, Himedia, India) by pour plate method in triplicates, incubated at $30 \pm 0.2^{\circ} \mathrm{C}$ for 24 to $48 \mathrm{~h}$ and total bacterial and vibrio counts were enumerated and expressed as colony forming units per gram of sediment ( $\left.\mathrm{cfu} \mathrm{g}^{-1}\right)$.

The data were analysed using one way ANOVA $(p<0.05)$ employing SPSS software.

Results of the present study revealed no significant difference in water quality parameters such as temperature, salinity, $\mathrm{pH}$ and $\mathrm{DO}$ between the two stations during the study period. Water quality in the net cage farm directly influenced the health of the ecosystem and the productivity of the culture system (Philipose et al., 2012). In the present study, mean surface water temperature ranged from 26.8 to $31.2^{\circ} \mathrm{C}( \pm 0.02)$ and 27.2 to $31.8^{\circ} \mathrm{C}$ $( \pm 0.02)$, whereas bottom water temperature ranged from 25.2 to $31.0^{\circ} \mathrm{C}( \pm 0.02)$ and 27.0 to $30.5^{\circ} \mathrm{C}( \pm 0.01)$ in the station 1 and station 2, respectively (Fig. 2a). Water temperature plays an important role in dissolution of gases and distribution of nutrients (Anusuya Devi et al., 2015). Present study exhibited fluctuations in water temperature in both stations during the study period, with lowest temperature recorded during the month of January and highest during May and this could be attributed to increased solar radiation during summer months.

Mean surface water salinity ranged from 14 to $33 \%$ $( \pm 0.02)$ and 14 to $34 \%$ o $( \pm 0.02)$ in station 1 and station 2 , respectively, whereas bottom water salinity ranged from 26 to $35 \mathrm{ppt}$ in both the stations (Fig. 2b). Salinity is one of the limiting factors that influences functional physiology and reproductive activity of marine organisms (Kinne, 1971). In the present study, lowest salinity was observed during the month of September, which could be attributed to the influx of freshwater from land run off during monsoon. Maximum salinity was recorded during the period March to May, which could be due to evaporation during postmonsoon season (James et al., 2015). Similar observations were reported by Prema et al. (2010) from the cage farm at Munambam, off Cochin coast, India.

Mean surface water DO ranged from 4.60 to $6.80 \mathrm{mg} \mathrm{l}^{-1}( \pm 0.02)$ and 4.70 to $6.72 \mathrm{mg} \mathrm{l}^{-1}( \pm 0.02)$, whereas bottom water DO ranged from 3.38 to $5.61 \mathrm{mg} \mathrm{l}^{-1} \quad( \pm 0.02)$ and 3.45 to $7.7 \mathrm{mg} \mathrm{l}^{-1}( \pm 0.01)$ in station 1 and station 2, respectively (Fig. 2c). Concentration of oxygen in water influences the health of culture system. DO is an essential factor influencing osmotic regulation and assimilation of digested food (Tom, 1998). Lower concentration of oxygen is reported to cause decrease in the growth, increased stress, lowering of immunity and susceptibility to infectious agents (Price et al., 2015). Further, concentration of oxygen in water in turn influences the solubility of nutrients, thereby causing shifts in the redox potential of the medium (Elahi et al., 2015). In the present study, the DO recorded in the bottom water was lower than the surface, which can be attributed to low solubility of oxygen in saline waters (Sujatha et al., 2009).

Mean $\mathrm{pH}$ value for surface water ranged from 7.5 to $8.3( \pm 0.03)$ and from 7.8 to $8.4( \pm 0.02)$ in station 1 and station 2 , respectively, whereas $\mathrm{pH}$ value for bottom water ranged from 7.6 to $8.3( \pm 0.02)$ in both the stations (Fig. 2d). Variations in $\mathrm{pH}$ values affect the survival, metabolism, physiology and growth of aquatic organisms (Anusuya Devi et al., 2015). The $\mathrm{pH}$ of coastal water is influenced by changes in dissolved carbon dioxide concentration, alkalinity and hydrogen ion concentration. Decomposition of organic matter in presence of dissolved oxygen increases the concentration of carbon dioxide and lowers the $\mathrm{pH}$ value (James et al., 2015). In the present study $\mathrm{pH}$ value of water from both the stations remained alkaline throughout the study period. 


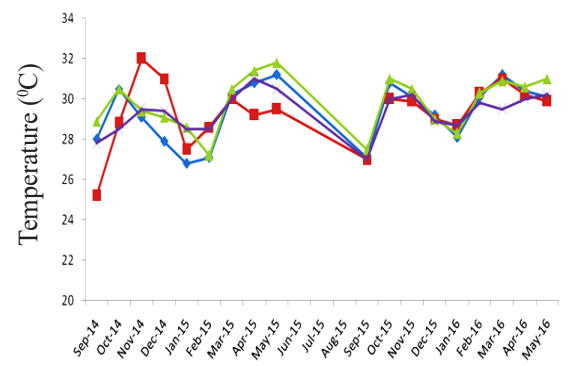

(a)

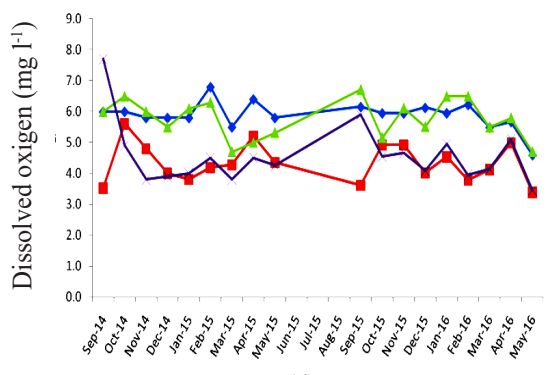

(d)

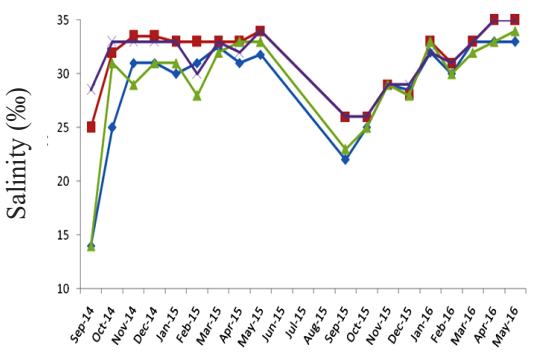

(b)

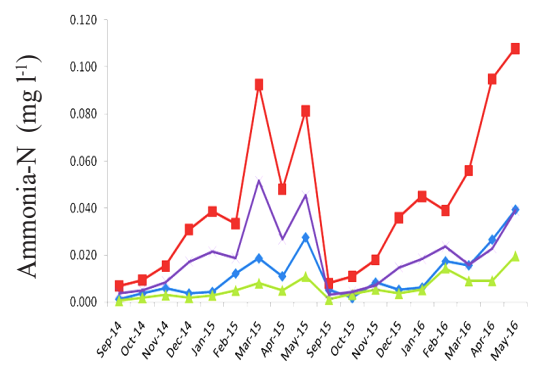

(e)

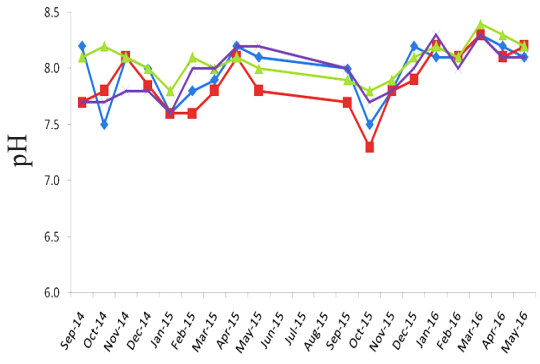

(c)

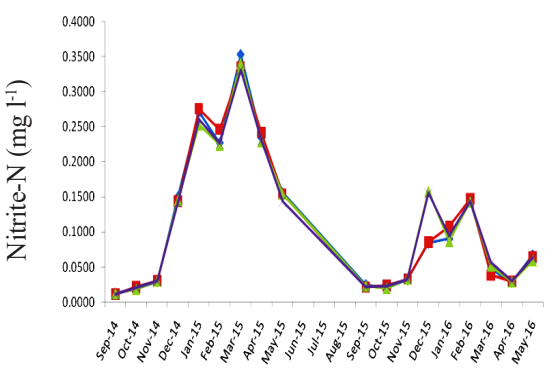

(f)

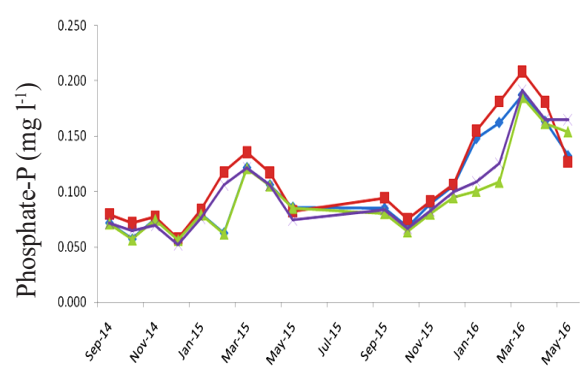

(g)

Fig. 2. Physicochemical parameters recorded at station 1 and 2 during the study period (September 2014-May 2016). (a): Water temperature, (b) : Water salinity, (c) : Dissolved oxygen, (d) pH, (e) : Ammonia nitrogen, (f) Nitrite nitrogen, (g) Inorganic phosphate

No significant variation was observed in the ammonianitrogen and nitrate-nitrogen values, whereas significant difference was observed in total dissolved inorganic phosphate values $(\mathrm{p}<0.05)$. Mean surface water ammonia ranged from 0.001 to $0.039 \mathrm{mg} \mathrm{l}^{-1} \quad( \pm 0.01)$ and 0.001 to $0.020 \mathrm{mg} \mathrm{l}^{-1}( \pm 0.03)$ in station 1 and station 2, respectively, whereas bottom water ammonia ranged from 0.007 to $0.108 \mathrm{mg} \mathrm{l}^{-1}( \pm 0.02)$ and 0.003 to $0.052 \mathrm{mg} \mathrm{l}^{-1}( \pm 0.03)$ in station 1 and 2, respectively (Fig. 2e). Mean surface water nitrite ranged from 0.013 to $0.353 \mathrm{mg} \mathrm{l}^{-1}( \pm 0.02)$ and 0.012 to $0.341 \mathrm{mg} \mathrm{l}^{-1}( \pm 0.04)$, whereas bottom water nitrite ranged from 0.011 to $0.335 \mathrm{mg} \mathrm{l}^{-1}( \pm 0.03)$ and 0.011 to $0.331 \mathrm{mg} \mathrm{l}^{-1}( \pm 0.02)$ in station 1 and 2 , respectively (Fig. 2f). Mean surface water phosphate ranged from 0.057 to $0.188 \mu \mathrm{g} \mathrm{l}^{-1}( \pm 0.02)$ in station 1 and 0.056 to

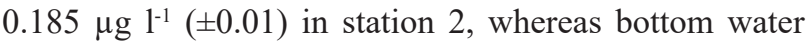
phosphate ranged from 0.057 to $0.209 \mu \mathrm{g} \mathrm{l}^{-1}( \pm 0.01)$ and 0.052 to $0.192 \mu \mathrm{g}^{-1}( \pm 0.03)$ in station 1 and 2 , respectively (Fig. 2g).
Intensive farming of fishes in the cage results in accumulation of organic matter in the sediment leading to progressive transformation of the substrate to anoxic environment as a result of bacterial degradation (Mazzola et al., 2000). The consequent risk of physicochemical pollution is restricted to the immediate vicinities of the farm (Wu et al., 1994; Wu, 1995). Fish cage releases soluble wastes such as ammonia, nitrate and phosphate. as excretory products directly into the water along with uneaten feed, containing high amount of protein and other nutrients (Price et al., 2015). Enrichment of water with nutrients results in acceleration of primary productivity and undesirable disturbance of the ecosystem. Observed values of the nutrients such as ammonia, nitrite and phosphate during the present study were lower than the values that can be considered harmful for the fish (Prema et al., 2010; Philipose et al., 2012).

Total cultivable bacterial count ranged from $2.06-19.27 \times 10^{4} \mathrm{cfu} \mathrm{g}^{-1}$ and $1.14-8.41 \times 10^{4} \mathrm{cfu} \mathrm{g}^{-1}$ 
(Fig. 3a), while total presumptive vibrio count ranged from 0.15 to $1.57 \times 10^{4} \mathrm{cfu} \mathrm{g}^{-1}$ and 0.09 to $0.78 \times 10^{4} \mathrm{cfu}$ $\mathrm{g}^{-1}$ in station 1 and 2, respectively (Fig. 3b). Enumeration of microbial assemblages in environmental samples of the cage farms has become an alternative approach for more reliable monitoring of contamination in coastal waters (Porrello et al., 2005; Zeng et al., 2010; Gorlach-Lira, 2013). In the present study, no significant difference was observed in total bacteria and presumptive vibrio counts between the two stations. However, the total bacterial and vibrio loads were higher in station 1 compared to station 2. A positive correlation was observed between the bacterial count and temperature, with the highest count of $19.27 \times 10^{4} \mathrm{cfu} \mathrm{g}^{-1}$, observed during May 2016. Similar

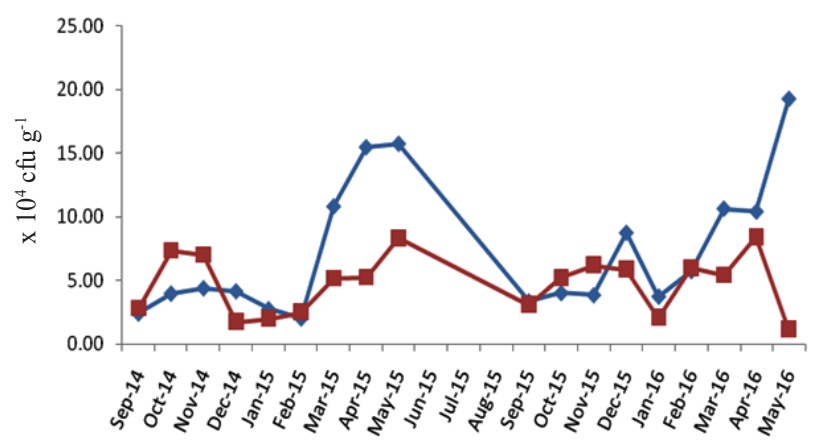

(a) results were reported by Prema et al. (2010), Philipose et al. (2012) and Jayasree et al. (2016).

To conclude, open sea cage farms are subjected to variations in the physicochemical parameters and microbial loads and regular monitoring of limnological and microbial biomass serve as sensitive indicators of the farm environment. In the present study, net cage farming with minimum number of cages for short culture period did not produce any noticeable impact on the water and sediment quality. However, there is need to monitor the cage environment regularly to understand the long term effects of the net cage culture on the water quality and sediment characteristics.

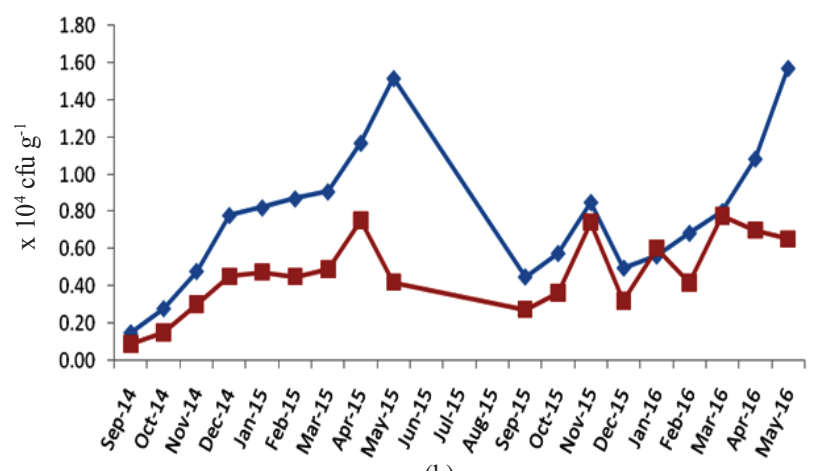

(b)

Fig. 3. (a) Total bacterial load and (b) Presumptive vibrio load recorded in the sediment at station 1 and 2 during the study period (September 2014-May 2016)

\section{Acknowledgements}

Authors are thankful to Dr. A. Gopalakrishnan, Director ICAR-Central Marine Fisheries Research Institute (ICAR-CMFRI), Kochi, India and Dr. K. K. Philipose, former Scientist-in-Charge, Karwar Research Centre of ICAR-CMFRI for providing facilities to carry out this work. Authors also thank Dr. S. R. Krupesha Sharma, Principal Scientist ICAR-CMFRI, for the scientific advice and critical review of the manuscript. Thanks are due to the staff members of the Department of Fisheries, Govt. of Goa.

\section{References}

Anusuya Devi, P., Padmavathy, P., Srinivasan, A. and Jawahar, P. 2015. Environmental impact of cage culture on Poondi Reservoir, Tamil Nadu. Curr. World. Environ., 10(3): 1048-1054.

APHA 1984. Standard methods for the examination of water and wastewater, $15^{\text {th }}$ edn. American Public Health Association, Washington D. C., USA.

Arulampalam, P., Yusoff, F. M., Shariff, M., Law, A. T. and Srinivasa Rao, P. S. 1998. Water quality and bacterial populations in a tropical marine cage culture farm. Aquac. Res., 29: 617-624.
Elahi, N., Ahmed, Q., Bat, L. and Yousuf, F. 2015. Physicochemical parameters and seasonal variation of coastal water from Balochistan coast, Pakistan. J. Coast. Life. Med., 3(3): 199-203.

Gorlach-Lira, K., Pacheco, C., Carvalho, L. C. T., Melo Junior, H. N. and Crispim, M. C. 2013. The influence of fish culture in floating net cages on microbial indicators of water quality. Braz. J. Biol., 73(3): 457-463.

James, B. A. D., Mary, J. K. S. and Vijaya Kumar, P. 2015. Monthly variations of water quality along south-east coast of India. Int. J. Geol. Agric. Environ. Sci., 3(3): 10-15.

Kinne, O. 1971. Marine ecology. Wiley Inter-Science, London, $821 \mathrm{pp}$.

Liao, I. C., Huang, T. S., Tsai, W. S., Hsueh, C. M., Chang, S. L. and Leano, E. M., 2004. Cobia culture in Taiwan: Current status and problems. Aquaculture, 237: 155-165.

Jayasree Loka, Philipose, K. K., Vaidya, N. G., Sonali, S. M. and Dube, P. N. 2016. Variations in growth rates of cage cultured Asian seabass Lates calcarifer (Bloch, 1790) and cobia Rachycentron canadum (Linnaeus, 1766) in relation to environmental quality of marine farm at Karwar, India Indian. J. Fish., 63(3): 139-144. 
Mazzola, A., Mirto, S., La Rosa, T., Fabiano, M. and Danovaro, R. 2000. Fish-farming effects on benthic community structure in coastal sediments: Analysis of meiofaunal recovery. J. Mar. Sci., 57: 1454-1461.

Moriarty, D. J. W. 1997. The role of micro-organisms in aquaculture ponds. Aquaculture., 151: 333-349.

Philipose, K. K., Krupesha Sharma, S. R., Jayasree Loka, Divu, D., Rao, G. S., Vaidya, N. G., Mhaddolkar, S. S., Sadhu, N. and Dube, P. N. 2012. Observations on variations in physicochemical water parameters of marine fish cage farm off Karwar. Indian. J. Fish., 59(1): 83-88.

Philipose, K. K., Krupesha Sharma, S. R., Jayasree Loka, Divu, D., Sadhu, N. and Dube, P. N. 2013. Culture of Asian seabass (Lates calcarifer, Bloch) in open sea floating net cages off Karwar, South India. Indian. J. Fish., 60(1): 67-70.

Porrello, S., Tomassetti, P., Manzueto, L., Finoia, M. G., Mercatali, I. and Stipa, P. 2005. The influence of marine cages on the sediment chemistry in the Western Mediterranean Sea. Aquaculture, 249(1-4): 145-158.

Prema, D., Sobhana, K. S., Laxminarayana, A., Imelda-Joseph., Shoji Joseph., Boby Ignatius., Jeyabaskaran, R., Nandakumar, A., Khambadkar, L. R., Anilkumar, P. S., Shylaja, G. and Syda Rao, G. 2010. Observations on selected characteristics of water and sediment at the open sea cage culture site of Asian seabass Lates calcarifer (Bloch) off Cochin, south-west coast of India. Indian. J. Fish., 57(4): 53-59.

Price, C., Black, K. D., Hargrave, B. T. and Morris Jr., J. A. 2015. Marine cage culture and the environment: Effects on water quality and primary production. Aquac. Environ. Interact., 6: 151-174.

Sujatha, C. H., Benny, N., Raveendran, R., Fanimol, C. L. and Samantha, N. K. 2009. Nutrient dynamics in the two lakes of Kerala, India. Indian. J. Mar. Sci., 38(4): 451-456.

Teodorowicz, M. 2013. Surface water quality and intensive fish culture. Arch. Pol. Fish., 21: 65-111.

Tom, L.1998. Nutritional and feeding of fish, $2^{\text {nd }}$ edn. Kluwer Academic Publishers, London.

Wu, R. S. S. 1995. The environmental impact of marine fish culture: Towards a sustainable future. Mar. Pollut. Bull., 31: 159-166.

Wu, R. S. S., Lam, K. S., MacKay, D. W., Lau, T. C. and Yam, V. 1994. Impact of marine fish farming on water quality and bottom sediment: A case study in the sub-tropical environment. Mar. Environ. Res., 38: 115-145.

Zeng, Y., Ma, Y., Wei, C., Jiao, N., Tang, K., Wu, Z. and Jian, J. 2010. Bacterial diversity in various coastal mariculture ponds in South-east China and in diseased eels as revealed by culture and culture-independent molecular techniques. Aquac. Res., 41: $172-186$.

Date of Receipt $\quad$ : 04.05.2017

Date of Acceptance : 11.09 .2017 